\title{
EFFECTS OF SWITCHING COSTS ON INNOVATIVE INVESTMENT
}

\author{
Pu-yan NIE ${ }^{1 \star}$, Chan WANG ${ }^{2}$, You-hua $\mathrm{CHEN}^{3}$, Yong-cong YANG \\ 1, 2 School of Finance, Institute of Guangdong Economy \& Social Development, \\ Collaborative Innovation Center of Scientific Finance \& industry, \\ Guangdong University of Finance \& Economics (GDUFE), Guangzhou, 510320, P.R. China \\ ${ }^{3}$ College of Economics \& Management and Guangdong Center for Rural Economic Studies, \\ South China Agricultural University, 510642, Guangzhou, PR. China \\ ${ }^{4}$ Institute of Studies for the Great Bay Area, Guangdong University of Foreign Studies, \\ Guangzhou 510420, P.R. China
}

Received 21 July 2017; accepted 17 March 2018

\begin{abstract}
Switching costs and innovation are two major issues in economics. Prior research demonstrates the effects of switching costs on competition, but ignores the influence of switching costs to firm innovation. So the purpose of this study is to reveal the relationships between switching costs and cost-reducing innovation by considering brand loyalty. All our theoretical conclusions are captured by game theory based on a two-stage duopoly model. The conclusions of this study show that under moderate conditions, switching costs improve competition. Strong firms implement lower price when switching costs are present than when they are not present. Second, at the asymmetric equilibrium, lower-efficiency firms with switching costs launch less innovative investments than do those without switching costs, while higher-efficiency firms with switching costs launch more innovation. But under symmetric equilibrium, switching costs have no effect on innovative investment. The novel contributions of this paper are that we find switching costs and loyalty have vertical impacts on firms' cost-reducing innovation, which extends the theory of switching costs.
\end{abstract}

Keywords: Switching cost, cost-reducing innovation, competition, commitment, game theory.

JEL Classification: C73, D21, L13.

\section{Introduction}

When consumers attempt to change a brand, switching costs arise as either contractual obligations or specific costs incurred to replace or to reacquire products. Switching costs are notably common, and it is crucial to capture their effects. Burnham, Krels, \& Mahajan (2003) identify three types of switching costs based on many social phenomena: procedural switching costs, financial switching costs and relational switching costs.

*Corresponding author. E-mail: pynie2013@163.com

This is an Open Access article distributed under the terms of the Creative Commons Attribution License (http://creativecommons. org/licenses/by/4.0/), which permits unrestricted use, distribution, and reproduction in any medium, provided the original author and source are credited. 
The relationship between switching costs and competition is a notably important topic in the fields of economics and management and has attracted extensive attention. But no consistent conclusions about the relationship between switching costs and competition are achieved. Besides, existed study of this issue has not take full consideration of innovation and brand loyalty, while these two factors have important influence on the relationship between switching costs and competition. The major purpose of this study is to fill up the gap we mentioned above and the novel contributions of this paper fall in two aspects as following.

First, we reveal the effects of switching costs on firm's exploitative innovation, cost-reducing innovation. Cost-reducing innovation means firm invest in innovation to reduce it production costs. Lower cost enable firm to reduce its price and plunder consumers from the competitor. Higher switching costs diminish the advantages of strong firms, but stimulate weak firms to improve their position by innovation. In other words, switching costs along with innovation reduce the difference between different efficiency firms.

Second, brand loyalty is important in innovation competition and we demonstrate the notable effects of loyalty on exploitative innovation. Loyalty has asymmetric influence to different efficiency firms. Comparing with lower-efficiency firms, higher-efficiency firms have more motivation to enforce innovation under switching costs because switching costs deter consumers to change product from different firm. And please notice that brand loyalty in our paper is different from the prior studies, such as Klemperer (1987) because we issue that brand loyalty only has long-term effects on competition but has no influence on new consumers.

In general, large switching costs lock in a buyer after an initial purchase. This study further examines this relationship under innovative investment. No price discrimination is introduced in this work. Because there are rare papers regarding innovation with switching costs, this paper fills this gap in the body of research and shows that switching costs yield lower prices. At the asymmetric equilibrium, switching costs cause lower innovative investment for firms with lower efficiency and higher innovation for firms with higher efficiency. At the symmetric equilibrium, switching costs have no relation with innovative investment. Our assumption of the convex cost functions is very popular in microeconomics and industrial organization.

The rest of this paper is organized as follows: Literature review is launched in Section 1. A two-period model is established in Section 2. The model is subsequently discussed, highlighting the relationships between switching costs and both competition and innovation in Section 3. Further discussion is outlined in Section 4. Concluding remarks are presented in the final section.

\section{Literature review}

The effects of switching costs on competition are not consistent in different studies. For example, Klemperer (1995) hypothesizes that switching costs make the market less competitive. Many other papers concerning switching costs also conclude that they make a market less competitive. But there is also extensive research on the positive effects of switching costs on competition. Dubé, Hitsch, \& Rossi (2009) challenge the presumption of Klemperer (1995). 
These authors propose a conclusion derived from numerical simulation that concludes that switching costs yield more competition. Cabral (2009) establishes a rational model to explain these phenomena successfully. Doganoglu (2010) further highlights switching costs with uncertain demands and also concludes that small switching costs improve competition. Viard (2007) also confirms that switching costs yield more competition. Considering switching costs, Shen and $\mathrm{Su}$ (2015) recently compared the contracts.

In their interesting survey paper, Farrell and Klemperer (2007) remark on significant conclusions related to switching costs and conclude that switching costs improve price. Chen (1997) develops a useful two-stage model with two firms to analyze switching costs and price discrimination strategies for old customers versus new ones. There is no shortage of discussion of switching costs in the literature, most of which highlight switching costs with dynamic problems. Morita and Waldman (2010) discuss monopoly maintenance with switching costs and explain the relationship between efficiency and monopolization. Wang and Wen (1998) address switching costs faced by a new entrant. Chen and Pearcy (2010) discuss brand switching in dynamic environments. Capone, Malerba, \& Orsenigo (2013) examined the relationship between switching costs and first-move advantage. Haj-Salem and Chebat (2014) pointed two effects of switching costs. Fischer and Ross (2014) examined the switching costs in material substitution projects. Jabarnejad and Valenzuela (2016) remarked that the switching costs exist in electric transmission systems.

This paper closely relates to innovation literature. For innovative investment, this study refers to the interesting papers of Sacco and Schmutzler (2011), Chen, Nie, and Wang (2015), Nie and Chen (2012), Nie (2014), Chen, Nie and Huang (2017), Chen, Nie, and Wen (2015b), Nie, Yang, Chen, and Wang (2016), Nie (2018), Chen and Sappington (2010), Yang, Nie, Liu, and Shen (2018), Nie, Wang, Chen, and Chen (2018), Chen, Wen, Wang, and Nie (2017) and Vives (2008). Chen and Sappington (2010) argue that vertical integration (VI) generally enhances innovation under downstream Cournot competition. Nie and Yang (2015), and, Wang, Nie, Peng, and Li (2017) discussed the relationship between subsidy and innovative investment. Farrell and Saloner (1985) point out that there is always excess inertia under a platform of incomplete information. This study further discusses this topic in detail with a two-period model.

\section{Model with switching costs and innovation}

The model's goal is to capture the relationship between switching costs and innovative investment. We refer to a two-period model combined with the innovative investment of Sacco and Schmutzler (2011). This study highlights effects of switching costs on innovation, which differs from Dubé et al. (2009) and Cabral (2009). Notations are presented as follows: $F=\{1,2\}$ represents two firms. The products of the two firms are functionally identical. There are two periods in all. $s$ is the switching costs and $p_{t}=\left(p_{t}^{1}, p_{t}^{2}\right)$ represents the price of two firms at period $t$ for $t=1,2 . \theta_{i} \in[0,1]$ stands for the degree of loyalty to a firm $i$ for $i=1,2$, which observes some type of distribution with dense function $f_{i}\left(\theta_{i}\right)$. This study always assumes that this distribution is uniform, or $f_{i}\left(\theta_{i}\right)=1$. All consumers may buy a unit product, and the market size is no more than 1 . This paper addresses switching costs based on brand 
loyalty. This paper assumes either that new consumers have no knowledge of brand value or that brand value has no effect on new consumers. $u_{0}=1$ is a constant, which means the maximum reservation utility for all consumers, and $\rho u_{0}=\rho$ stands for the utility of a consumer with parameter $\rho \in[0,1]$ with which to consume a unit product. The utility value, for certain consumers consuming from firm $i$ at the first period for $i=1,2$, is:

$$
u_{1}\left(p_{1}^{i}\right)=\rho u_{0}-p_{1}^{i}=\rho-p_{1}^{i} .
$$

$\rho \in[0,1]$ is a random variable observing uniform distribution that reflects the wealthlevel of consumers. Consumers buy products if and only if $\max u_{1}\left(p_{1}{ }^{i}\right) \geq 0$. At the second period, the utility value of consumers with brand loyalty $\theta_{i} \in[\dot{0}, 1]$ is $u_{2}\left(p, \theta_{i}\right)=\theta_{i}+\rho-p_{2}^{i}$. A consumer changes their product from firm $i$ to firm $j$ with $i \neq j$ at the second period, if and only if the following relation holds,

$$
\theta_{i}-p_{2}^{i} \leq-p_{2}^{j}-s
$$

Eq. (2) implies that the utility value is increased if this consumer changes their product. Moreover, a consumer changes their product and he/she regards the degree of brand loyalty to a new product to be zero. Some consumers entering into this market at period 2 buy only products with lower prices, and the utility value of these consumers is $u_{2}\left(p_{2}\right)=\rho-\min \left\{p_{2}^{1}, p_{2}^{2}\right\}$.

$q_{t}=\left(q_{t}^{1}, q_{t}^{2}\right)$ represents output quantity of two firms at period $t$ for $t=1,2$. Two firms launch innovative investment at the first stage and the marginal cost of the two firms at the second period is determined by both innovative investment at the first period and the product quantity at the second period. Two firms identically price at the first stage, or $p_{1}^{1}=p_{1}^{2}$. Moreover, two firms establish their brand and brand loyalty ${ }^{1} I_{i} \geq 0$ is the innovative investment for firm $i . c_{i}\left(I_{i}\right)$ is the cost incurred to produce a unit product of firm $i$ at period 2 . Discounting factors of the two firms are identical and are held at 1 to simplify the model. This study on switching costs is based on (2), and the net profit of firm $i$, for $i=1,2$, is:

$$
\pi^{i}=\left(p_{1}^{i}-c_{0}\right) q_{1}^{i}+\left[p_{2}^{i}-c_{i}\left(I_{i}\right)\right] q_{2}^{i}\left(p_{2}, s, q_{1}\right)-\frac{1}{2} I_{i}^{2} .
$$

$\frac{1}{2} I_{i}^{2}$ is the cost of innovative investment incurred by firm $i$, which is similar to Sacco and Schmutzler (2011). $\left(p_{1}^{i}-c_{0}\right) q_{1}^{i}-\frac{1}{2} I_{i}^{2}$ is the net profit at the first period and $\left[p_{2}^{i}-c_{i}\left(I_{i}\right)\right] q_{2}^{i}\left(p_{2}, s, q_{1}\right)$ is the net profit of firm $i$ at the second period. In (3), for $i=1,2$, we have:

$$
q_{2}^{i}=q_{1}^{i}-\int_{0}^{\theta_{i}^{*}} d \theta_{i}+\int_{0}^{\theta_{j}^{*}} d \theta_{j}+q_{2}^{i, N}
$$

where $\theta_{i}^{*}=\max \left\{0, p_{2}^{i}-p_{2}^{j}-s\right\}$ and $\theta_{j}^{*}=\max \left\{0, p_{2}^{j}-p_{2}^{i}-s\right\} \cdot q_{2}^{i, N}$ denotes the number of

\footnotetext{
${ }^{1}$ This brand loyalty differs from that of Klemperer (1987), which has effects on firms' strategies at two periods. We always assume that the brand value has no effects on the new consumers. In this paper, the brand loyalty is established in the first period and has effects on firms' strategies at the second period. For example, new cellular phone consumers neglect switching costs at the first stage. At the second stage, many cellular phone carriers charge high cancellation fees for canceling a contract. Cell phone carriers present these charges in the hope that the costs involved with switching to another carrier will be high enough to prevent their customers from doing so. (http://www.investopedia.com/terms/s/switchingcosts.asp\#ixzz1lBMQCO4l).
} 
new consumers who enter this market at the second period. If $p_{2}^{i}>p_{2}^{j}$, according to the utility function $(1), u_{2}\left(\min \left\{p_{2}^{1}, p_{2}^{2}\right), 0\right)-u_{1}\left(p_{1}{ }^{i}\right)=\left(\rho-\min \left\{p_{2}^{1}, p_{2}^{2}\right)\right)-\left(\rho-p_{1}^{i}\right) \geq 0$, and there are no new consumers to buy products from firm $i$. If $p_{2}^{i}<p_{2}^{j}$ and $p_{1}-\min \left\{p_{2}^{1}, p_{2}^{2}\right\}>0$, by (1) there are $p_{1}-\min \left\{p_{2}^{1}, p_{2}^{2}\right\}>0$ new consumers. Otherwise, there are 0 new consumers. Therefore, from (1), we have the relationship $q_{2}^{i, N}=\left\{\begin{array}{cc}0 & p_{2}^{i}>p_{2}^{j} \\ \max \left\{0, p_{1}-\min \left\{p_{2}^{1}, p_{2}^{2}\right\}\right\} & p_{2}^{i}<p_{2}^{j}\end{array}\right.$. Eq. (4) means that the output of firm $i$ at the second period is equal to the output of the first period plus the change in output of the rival firm, plus new consumers gained at the second period, minus consumers changing from firm $i$ to other firms.

For convenience, we must abstract from other important factors discussed in the literature, such as holdup and others. By virtue of duopoly, market clearing conditions always hold. Moreover, the following assumption is launched.

Assumption: $c_{i}\left(I_{i}\right)$ is convex in $I_{i} \geq 0$ and $\frac{d c_{i}\left(I_{i}\right)}{d I_{i}}<0$ for $i=1,2$. Moreover, $c_{i}(0)=c_{0}$. $\frac{d c_{i}\left(I_{i}\right)}{d I_{i}}<0$ implies that innovative investment can efficiently reduce production cost. $c_{i}\left(I_{i}\right)$ is convex such that (3) is concave in $I_{i}$ to guarantee the existence of optimal innovative investment. $c_{i}(0)=c_{0}$ implies that the cost is not changed without innovative investment. Chen (1997) develops a model with two periods and two firms to capture switching costs, arriving at a number of interesting conclusions. However, Chen (1997) addresses price discrimination, while this study highlights innovation under switching cost.

In this game, at the first period, two firms price and determine innovative investment, and consumers decide to buy products from one firm. If there is no difference between the two firms, consumers buy products randomly. At the second stage, the two firms price and consumers in this market decide whether to change products or not, and new consumers enter this industry.

\section{Model analysis}

In these calculations, we use the model in the above section to find an equilibrium solution. At the first period, $p_{1}^{1}=p_{1}^{2}=p_{1}$, Eq. (1) and market clearing conditions jointly imply $q_{1}^{1}+q_{1}^{2}=1-p_{1}$. Actually, $p_{1}^{1}=p_{1}^{2}=p_{1}$ along with $q_{1}^{1}=q_{1}^{2}=\frac{1-p_{1}}{2}$ is a Nash equilibrium if the two firms' strategy sets are all $S=$ \{optimally pricing, following rival's price $\}$. This equilibrium indicates that firms take their optimal price and their rival's price into account when they make decisions. Market clearing conditions and $u_{2}\left(p, \theta_{i}\right)=\theta_{i}+\rho-p_{2}^{i}$ at the second period manifest the relation $q_{2}^{1}+q_{2}^{2}=1-\min \left\{p_{2}^{1}, p_{2}^{2}\right\}$. By backward induction, the second period is addressed first followed by the first period.

\subsection{The second period}

The second period is discussed in several cases. If $p_{2}^{1}<p_{2}^{2}$, then according to the above analysis we have $q_{2}^{2, N}=0$ and $\int_{0}^{\theta_{1}^{*}} d \theta_{1}=0$. No new consumers buy products from firm 2 , 
and no consumers change their product from the first firm to the second one. We consider three cases of these conditions.

If $p_{2}^{2}-p_{2}^{1} \leq s$, we further have $\int_{0}^{\theta_{2}^{*}} d \theta_{2}=0$. There are no old consumers changing their products. The profits of two firms are given by the following formulation:

$$
\begin{gathered}
\pi^{1}=\left(p_{1}-c_{0}\right) q_{1}^{1}+\left[p_{2}^{1}-c_{1}\left(I_{1}\right)\right]\left[q_{1}^{1}+\left(p_{1}-p_{2}^{1}\right)\right]-\frac{1}{2} I_{1}^{2} ; \\
\pi^{2}=\left(p_{1}-c_{0}\right) q_{1}^{2}+\left[p_{2}^{2}-c_{2}\left(I_{2}\right)\right] q_{1}^{2}-\frac{1}{2} I_{2}^{2} .
\end{gathered}
$$

$\pi^{1}$ is concave in $p_{2}^{1}$ and $p_{2}^{1}$ is uniquely determined by first-order optimal conditions. $\frac{\partial \pi^{1}}{\partial p_{2}^{1}}=-2 p_{2}^{1}+q_{1}^{1}+p_{1}+c_{1}\left(I_{1}\right)=0$. We further achieve:

$$
p_{2}^{1}=\frac{1}{2} q_{1}^{1}+\frac{1}{2} p_{1}+\frac{1}{2} c_{1}\left(I_{1}\right) .
$$

$\pi^{2}$ is monotonically increasing in $p_{2}^{2}$ and $p_{2}^{2}-p_{2}^{1} \leq s$ implies that the second firm's optimal strategy is $p_{2}^{2}=p_{2}^{1}+s$. Moreover, $q_{2}^{1}=\frac{1}{2} q_{1}^{1}+\frac{1}{2} p_{1}-\frac{1}{2} c_{1}\left(I_{1}\right)$ and $q_{2}^{2}=q_{1}^{2}$. Thus, $p_{2}^{2}-p_{2}^{1} \leq s$ suggests $p_{2}^{1}=\frac{1}{2} q_{1}^{1}+\frac{1}{2} p_{1}+\frac{1}{2} c_{1}\left(I_{1}\right)$ and

$$
p_{2}^{2}=p_{2}^{1}+s
$$

If $s<p_{2}^{2}-p_{2}^{1} \leq s+1$, the profits of the two firms are

$$
\begin{gathered}
\pi^{1}=\left(p_{1}-c_{0}\right) q_{1}^{1}+\left[p_{2}^{1}-c_{1}\left(I_{1}\right)\right]\left[q_{1}^{1}+\left(p_{1}-p_{2}^{1}\right)+\left(p_{2}^{2}-p_{2}^{1}-s\right)\right]-\frac{1}{2} I_{1}^{2} \\
\pi^{2}=\left(p_{1}-c_{0}\right) q_{1}^{2}+\left[p_{2}^{2}-c_{2}\left(I_{2}\right)\right]\left[q_{1}^{2}-\left(p_{2}^{2}-p_{2}^{1}-s\right)\right]-\frac{1}{2} I_{2}^{2} .
\end{gathered}
$$

$\pi^{1}$ is concave in $p_{2}^{1}$ and $\pi^{2}$ is concave in $p_{2}^{2}$. There exists a unique solution under this situation, which is determined by the first optimal conditions that satisfy the following:

$$
\begin{gathered}
\frac{\partial \pi^{1}}{\partial p_{2}^{1}}=-4 p_{2}^{1}+q_{1}^{1}+p_{1}+p_{2}^{2}-s+2 c_{1}\left(I_{1}\right)=0 ; \\
\frac{\partial \pi^{2}}{\partial p_{2}^{2}}=p_{2}^{1}+q_{1}^{2}-2 p_{2}^{2}+s+c_{2}\left(I_{2}\right)=0 .
\end{gathered}
$$

From the above equations, we achieve:

$$
p_{2}^{1}=\frac{2}{7} q_{1}^{1}+\frac{1}{7} q_{1}^{2}+\frac{2}{7} p_{1}-\frac{s}{7}+\frac{4}{7} c_{1}\left(I_{1}\right)+\frac{1}{7} c_{2}\left(I_{2}\right)
$$

and

$$
p_{2}^{2}=\frac{1}{7} q_{1}^{1}+\frac{4}{7} q_{1}^{2}+\frac{1}{7} p_{1}+\frac{3 s}{7}+\frac{2}{7} c_{1}\left(I_{1}\right)+\frac{4}{7} c_{2}\left(I_{2}\right)
$$


Furthermore, we have the relations $q_{2}^{1}=\frac{4}{7} q_{1}^{1}+\frac{2}{7} q_{1}^{2}+\frac{4}{7} p_{1}-\frac{2}{7} s-\frac{6}{7} c_{1}\left(I_{1}\right)+\frac{2}{7} c_{2}\left(I_{2}\right)$ and $q_{2}^{2}=\frac{1}{7} q_{1}^{1}+\frac{4}{7} q_{1}^{2}+\frac{1}{7} p_{1}+\frac{3}{7} s+\frac{2}{7} c_{1}\left(I_{1}\right)-\frac{3}{7} c_{2}\left(I_{2}\right)$.

If $p_{2}^{2}-p_{2}^{1}>s+1, q_{2}^{2}=0$. The profits of the two firms are outlined by the following formulation:

$$
\begin{gathered}
\left.\pi^{1}=\left(p_{1}-c_{0}\right) q_{1}^{1}+\left[p_{2}^{1}-c_{1}\left(I_{1}\right)\right]\left(1-p_{2}^{1}\right)\right]-\frac{1}{2} I_{1}^{2} \\
\pi^{2}=\left(p_{1}-c_{0}\right) q_{1}^{2} .
\end{gathered}
$$

$\pi^{1}$ is concave in $p_{2}^{1}$ and the optimal strategy is determined by the following equation. $\frac{\partial \pi^{1}}{\partial p_{2}^{1}}=-2 p_{2}^{1}+1+c_{1}\left(I_{1}\right)=0$. We further have:

$$
p_{2}^{1}=\frac{1}{2}+\frac{c_{1}\left(I_{1}\right)}{2} .
$$

In this situation, the second firm exits this market and the first firm acts as a monopolist at the second period. $q_{2}^{1}=\frac{1}{2}-\frac{c_{1}\left(I_{1}\right)}{2}$ and $q_{2}^{2}=0$. Under $p_{2}^{2}-p_{2}^{1}>s+1$, we have $p_{2}^{1}=\frac{1}{2}+\frac{c_{1}\left(I_{1}\right)}{2}$ and the second firm exits at the second period.

If, $p_{2}^{1}>p_{2}^{2}$, we have similar conclusions, and a similarly detailed discussion is omitted.

\subsection{The first period}

At the first period, the two firms' strategy sets are all $S=$ \{optimally pricing, following rival's price\}. Therefore, the profit function is non-smooth. In this calculation, we address each element of the Nash equilibrium separately. For innovative investment, we find, if $p_{2}^{2}-p_{2}^{1} \leq s+1$

$$
\frac{d c_{1}\left(I_{1}\right)}{d I_{1}} q_{2}^{1}=I_{1} \text { and } \frac{d c_{2}\left(I_{2}\right)}{d I_{2}} q_{2}^{2}=I_{2} .
$$

Eq. (18) is the first optimal conditions of (5)-(6) and (9)-(10).

$$
\text { If } p_{2}^{2}-p_{2}^{1}>s+1, \frac{d c_{1}\left(I_{1}\right)}{d I_{1}} q_{2}^{1}=I_{1} \text { and } I_{2}=0 \text {. }
$$

Eq. (19) is the first optimal conditions of (15)-(16).

We further analyze price in the first period. If $p_{1}^{1}=p_{1}^{2}=p_{1}$, we further assume that $q_{1}^{1}=q_{1}^{2}=q_{1}=\frac{1}{2}\left(1-p_{1}\right)$. When two firms price identically, customers randomly buy products, and the expected quantity of products that will be sold is identical. To simplify, we assume that the quantity produced by two firms is identical. In this case, two firms determine their price according to the corresponding optimal price and the rival's price.

If $p_{2}^{2}-p_{2}^{1} \leq s$, from $q_{1}^{1}=q_{1}^{2}=q_{1}=\frac{1}{2}\left(1-p_{1}\right)$ and (5), we further have the following formulation: 


$$
\begin{aligned}
\pi^{1} & =\left(p_{1}-c_{0}\right) q_{1}^{1}+\left[p_{2}^{1}-c_{1}\left(I_{1}\right)\right]\left[q_{1}^{1}+\left(p_{1}-p_{2}^{1}\right)\right]-\frac{1}{2} I_{1}^{2} \\
& =\left(p_{1}-c_{0}\right) q_{1}^{1}+\left[\frac{1}{2} q_{1}^{1}+\frac{1}{2} p_{1}-\frac{1}{2} c_{1}\left(I_{1}\right)\right]^{2}-\frac{1}{2} I_{1}^{2} \\
& =\frac{1}{2}\left(p_{1}-c_{0}\right)\left(1-p_{1}\right)+\left[\frac{1}{4}\left(1-p_{1}\right)+\frac{1}{2} p_{1}-\frac{1}{2} c_{1}\left(I_{1}\right)\right]^{2}-\frac{1}{2} I_{1}^{2}, \\
\pi^{2}= & \left(p_{1}-c_{0}\right) q_{1}^{2}+\left[p_{2}^{2}-c_{2}\left(I_{2}\right)\right] q_{1}^{2}-\frac{1}{2} I_{2}^{2} \\
= & \frac{1}{2}\left(1-p_{1}\right)\left[\frac{1}{4}\left(1-p_{1}\right)+\frac{3}{2} p_{1}+\frac{1}{2} c_{1}\left(I_{1}\right)+s-c_{2}\left(I_{2}\right)-c_{0}\right]-\frac{1}{2} I_{2}^{2} .
\end{aligned}
$$

According to the above system, obviously, the profit function of the first firm is concave in $p_{1}$. The profit function of the second firm is also concave in $p_{2}$ for all $u_{0}$. After one firm launches a lower price, the other firms follow suit. The first optimal conditions of the first firm are:

$$
\frac{\partial \pi_{1}}{\partial p_{1}}=\frac{1}{2}\left(-2 p_{1}+c_{0}+1\right)+2\left[\frac{1}{4}\left(1-p_{1}\right)+\frac{1}{2} p_{1}-\frac{1}{2} c_{1}\left(I_{1}\right)\right]\left(\frac{1}{2}-\frac{1}{4}\right)=0 .
$$

Conversely, $p_{1}=\frac{5-2 c_{1}\left(I_{1}\right)+4 c_{0}}{7}$.

The first optimal conditions of the second firm are

$$
\frac{\partial \pi_{2}}{\partial p_{1}}=\frac{1}{2}\left(-2 p_{1}+c_{0}+1\right)-\frac{1}{2}\left[\frac{1}{4}\left(1-p_{1}\right)+\frac{1}{2} p_{1}+s+\frac{1}{2} c_{1}\left(I_{1}\right)-c_{2}\left(I_{2}\right)\right]+\frac{1}{8}\left(1-p_{1}\right)=0 .
$$

We have $p_{1}=\frac{2 c_{0}-2 s+2 c_{2}\left(I_{2}\right)-c_{1}\left(I_{1}\right)+2}{5}$. Furthermore, because $1>\max \left\{c_{1}\left(I_{1}\right), c_{2}\left(I_{2}\right)\right\}$, and $c_{0}>\max \left\{c_{1}\left(I_{1}\right), c_{2}\left(I_{2}\right)\right\}, \quad$ we have the relation $11-3 c_{1}\left(I_{1}\right)+6 c_{0}+14 s>14 c_{2}\left(I_{2}\right)$, or $\frac{5-2 c_{1}\left(I_{1}\right)+4 c_{0}}{7}>\frac{2 c_{0}-2 s+2 c_{2}\left(I_{2}\right)-c_{1}\left(I_{1}\right)+2}{5}$.

In this case,

$$
p_{1}^{*}=\min \left\{\frac{5-2 c_{1}\left(I_{1}\right)+4 c_{0}}{7}, \frac{2 c_{0}-2 s+2 c_{2}\left(I_{2}\right)-c_{1}\left(I_{1}\right)+2}{5}\right\}=\frac{2 c_{0}-2 s+2 c_{2}\left(I_{2}\right)-c_{1}\left(I_{1}\right)+2}{5} \text {. }
$$

Note: According to the definition of Nash equilibrium,

$$
p_{1}^{*}=\min \left\{\frac{5-2 c_{1}\left(I_{1}\right)+4 c_{0}}{7}, \frac{2 c_{0}-2 s+2 c_{2}\left(I_{2}\right)-c_{1}\left(I_{1}\right)+2}{5}\right\} \text { is a Nash equilibrium. }
$$

Conversely, for sufficiently small $s$, we have

$$
\begin{aligned}
& p_{2}^{1}-p_{1}^{*}=\frac{3}{14}-\frac{s}{7}+\frac{4}{7} c_{1}\left(I_{1}\right)+\frac{1}{7} c_{2}\left(I_{2}\right)-\frac{13}{14} \frac{2 c_{0}-2 s+2 c_{2}\left(I_{2}\right)-c_{1}\left(I_{1}\right)+2}{5} \\
& =-\frac{1}{70}+\frac{8}{35} s+\frac{53}{70} c_{1}\left(I_{1}\right)-\frac{16}{70} c_{2}\left(I_{2}\right)-\frac{13}{35} c_{0}<0 .
\end{aligned}
$$


If $s<p_{2}^{2}-p_{2}^{1} \leq s+1$, the profits of the two firms are

$$
\begin{aligned}
\pi^{1} & =\left(p_{1}-c_{0}\right) q_{1}^{1}+2\left[\frac{2}{7} q_{1}^{1}+\frac{1}{7} q_{1}^{2}+\frac{2}{7} p_{1}-\frac{1}{7} s-\frac{3}{7} c_{1}\left(I_{1}\right)+\frac{1}{7} c_{2}\left(I_{2}\right)\right]^{2}-\frac{1}{2} I_{1}^{2} \\
& =\frac{1}{2}\left(p_{1}-c_{0}\right)\left(1-p_{1}\right)+2\left[\frac{3}{14}\left(1-p_{1}\right)+\frac{2}{7} p_{1}-\frac{1}{7} s-\frac{3}{7} c_{1}\left(I_{1}\right)+\frac{1}{7} c_{2}\left(I_{2}\right)\right]^{2}-\frac{1}{2} I_{1}^{2} \\
\pi^{2} & =\left(p_{1}-c_{0}\right) q_{1}^{2}+\left[\frac{1}{7} q_{1}^{1}+\frac{4}{7} q_{1}^{2}+\frac{1}{7} p_{1}+\frac{3}{7} s+\frac{2}{7} c_{1}\left(I_{1}\right)-\frac{3}{7} c_{2}\left(I_{2}\right)\right]^{2}-\frac{1}{2} I_{2}^{2} \\
& =\frac{1}{2}\left(p_{1}-c_{0}\right)\left(1-p_{1}\right)+\left[\frac{5}{14}\left(1-p_{1}\right)+\frac{p_{1}}{7}+\frac{3}{7} s+\frac{2}{7} c_{1}\left(I_{1}\right)-\frac{3}{7} c_{2}\left(I_{2}\right)\right]^{2}-\frac{1}{2} I_{2}^{2} .
\end{aligned}
$$

In this case, profit functions of the two firms are all concave. The first optimal conditions of the two firms are:

$$
\begin{aligned}
& \frac{\partial \pi_{1}}{\partial p_{1}}=\frac{1}{2}\left(-2 p_{1}+c_{0}+1\right)+4\left[\frac{3}{14}\left(1-p_{1}\right)+\frac{2}{7} p_{1}-\frac{1}{7} s-\frac{3}{7} c_{1}\left(I_{1}\right)+\frac{1}{7} c_{2}\left(I_{2}\right)\right]\left(\frac{2}{7}-\frac{3}{14}\right)=0 \\
& \frac{\partial \pi_{2}}{\partial p_{1}}=\frac{1}{2}\left(-2 p_{1}+c_{0}+1\right)+2\left[\frac{5}{14}\left(1-p_{1}\right)+\frac{1}{7} p_{1}+\frac{3}{7} s+\frac{2}{7} c_{1}\left(I_{1}\right)-\frac{3}{7} c_{2}\left(I_{2}\right)\right]\left(\frac{1}{7}-\frac{5}{14}\right)=0 .
\end{aligned}
$$

From the profit of the firms, we immediately achieve:

$$
\begin{gathered}
p_{1}^{*}=\min \left\{\frac{27.5+24.5 c_{0}-6 c_{1}\left(I_{1}\right)+2 c_{2}\left(I_{2}\right)-2 s}{48}, \frac{34+49 c_{0}+18 c_{2}\left(I_{2}\right)-12 c_{1}\left(I_{1}\right)-18 s}{89}\right\} \\
=\frac{34+49 c_{0}+18 c_{2}\left(I_{2}\right)-12 c_{1}\left(I_{1}\right)-18 s}{89} .
\end{gathered}
$$

The second equality comes from the relation

$$
\frac{27.5+24.5 c_{0}-6 c_{1}\left(I_{1}\right)-2 c_{2}\left(I_{2}\right)-2 s}{48}>\frac{34+49 c_{0}+18 c_{2}\left(I_{2}\right)-12 c_{1}\left(I_{1}\right)-18 s}{89} .
$$

This relation holds because $\left.\frac{\partial \pi_{2}}{\partial p_{1}}\right|_{p_{1}=p_{1}^{*}}=0$, while $\left.\frac{\partial \pi_{1}}{\partial p_{1}}\right|_{p_{1}=p_{1}^{*}}>\left.\frac{\partial \pi_{2}}{\partial p_{1}}\right|_{p_{1}=p_{1}^{*}}=0$.

If $p_{2}^{2}-p_{2}^{1}>s+1$, the profits of two firms are outlined by the following formulation:

$$
\begin{gathered}
\pi^{1}=\frac{1}{2}\left(p_{1}-c_{0}\right)\left(1-p_{1}\right)+\frac{1}{4}\left[1-c_{1}\left(I_{1}\right)\right]^{2}-\frac{1}{2} I_{1}^{2} \\
\pi^{2}=\frac{1}{2}\left(p_{1}-c_{0}\right)\left(1-p_{1}\right) .
\end{gathered}
$$

In this case, we have $p_{1}^{*} \in \arg \max _{p_{1}}\left\{\frac{1}{2}\left(p_{1}-c_{0}\right)\left(1-p_{1}\right)\right\}$. Moreover, the price at the second period has no relation with the price at the first period. At the first period, equilibrium price 
is denoted by $p_{1}^{*}$. We now further discuss Equilibrium price. Based on the above analysis, we have the following conclusion

Proposition 1: For $i \neq j$ and $i, j=1,2$, under $p_{2}^{i}<p_{2}^{j}$, for equilibrium price, we have: $p_{1}^{*}$ and $p_{2}^{i}$ are all monotonically decreasing in $s$, while $p_{2}^{j}$ is monotonically increasing in s. $q_{2}^{i}$ and $I_{i}$ are all monotonically decreasing in $s$, while $q_{2}^{j}$ and $I_{j}$ are all monotonically increasing in $s$.

Proof. If $p_{2}^{2}-p_{2}^{1} \leq s$, we immediately achieve that $p_{1}^{*}$ is monotonically decreasing in $s$ from Eq. (22). When $s<p_{2}^{2}-p_{2}^{1} \leq s+1$, from Eq. (23), the term $\frac{34+49 c_{0}+18 c_{2}\left(I_{2}\right)-12 c_{1}\left(I_{1}\right)-18 s}{89}$ is monotonically decreasing in $s . p_{1}^{\star}$, therefore, is monotonically decreasing in $s$.

If $p_{2}^{2}-p_{2}^{1} \leq s, p_{2}^{1}=\frac{1}{2} q_{1}^{1}+\frac{1}{2} p_{1}+\frac{1}{2} c_{1}\left(I_{1}\right)=\frac{1}{4} p_{1}+\frac{1}{4}+\frac{1}{2} c_{1}\left(I_{1}\right)$ then Eq. (22) implies that $p_{2}^{1}$ is monotonically decreasing in $s$. For the price of the second firm, we have

$$
\begin{aligned}
p_{2}^{2} & =p_{2}^{1}+s=\frac{1}{4} p_{1}+\frac{1}{4}+\frac{1}{2} c_{1}\left(I_{1}\right)+s \\
& =\frac{2 c_{0}-2 s+2 c_{2}\left(I_{2}\right)-c_{1}\left(I_{1}\right)+2 u_{0}}{20}+\frac{1}{4}+\frac{1}{2} c_{1}\left(I_{1}\right)+s \\
& =\frac{2 c_{0}+18 s+2 c_{2}\left(I_{2}\right)-c_{1}\left(I_{1}\right)+2}{20}+\frac{1}{4}+\frac{1}{2} c_{1}\left(I_{1}\right) .
\end{aligned}
$$

Apparently, $p_{2}^{2}$ is monotonically increasing in $s$.

For $s<p_{2}^{2}-p_{2}^{1} \leq s+1$, we have $p_{2}^{1}=\frac{2}{7} q_{1}^{1}+\frac{1}{7} q_{1}^{2}+\frac{2}{7} p_{1}-\frac{s}{7}+\frac{4}{7} c_{1}\left(I_{1}\right)+\frac{1}{7} c_{2}\left(I_{2}\right)=$ $\frac{1}{14} p_{1}-\frac{s}{7}+\frac{4}{7} c_{1}\left(I_{1}\right)+\frac{1}{7} c_{2}\left(I_{2}\right)+\frac{3}{14} \cdot p_{2}^{1}$ is monotonically decreasing in $s$. For the second firm,

$$
\begin{aligned}
p_{2}^{2} & =\frac{1}{7} q_{1}^{1}+\frac{4}{7} q_{1}^{2}+\frac{1}{7} p_{1}+\frac{3 s}{7}+\frac{2}{7} c_{1}\left(I_{1}\right)+\frac{4}{7} c_{2}\left(I_{2}\right) \\
& =-\frac{3}{14} p_{1}+\frac{3 s}{7}+\frac{2}{7} c_{1}\left(I_{1}\right)+\frac{4}{7} c_{2}\left(I_{2}\right)+\frac{5}{14} .
\end{aligned}
$$

Because $p_{1}^{*}$ is monotonically decreasing in $s, p_{2}^{2}$ is monotonically increasing in $s$. Similarly, we have $p_{1}^{*}$ and $p_{2}^{2}$ all monotonically decreasing in $s$, while $p_{2}^{1}$ is monotonically increasing in $s$.

If $p_{2}^{2}-p_{2}^{1} \leq s$, we have

$$
\begin{aligned}
q_{2}^{1} & =\frac{1}{2} q_{1}^{1}+\frac{1}{2} p_{1}-\frac{1}{2} c_{1}\left(I_{1}\right)=\frac{1}{4}+\frac{1}{4} p_{1}-\frac{1}{2} c_{1}\left(I_{1}\right) \\
& =\frac{1}{4}+\frac{1}{4} \frac{2 c_{0}-2 s+2 c_{2}\left(I_{2}\right)-c_{1}\left(I_{1}\right)+2}{5}-\frac{1}{2} c_{1}\left(I_{1}\right) \\
& =\frac{1}{4}+\frac{1}{4} \frac{2 c_{0}-2 s+2 c_{2}\left(I_{2}\right)-11 c_{1}\left(I_{1}\right)+2}{5} .
\end{aligned}
$$

Obviously, $q_{2}^{1}$ is decreasing in $s$. If the profit function is concave in $I_{1}, I_{1}$ is also decreasing in $s$. The conclusion of the first firm is achieved under $p_{2}^{2}-p_{2}^{1} \leq s$. For the second firm, we have 


$$
\begin{aligned}
q_{2}^{2} & =q_{1}^{2}=\frac{1}{2}\left(1-p_{1}^{*}\right)=\frac{1}{2}-\frac{1}{2} \frac{2 c_{0}-2 s+2 c_{2}\left(I_{2}\right)-c_{1}\left(I_{1}\right)+2}{5} \\
& =\frac{1}{4}-\frac{1}{4} \frac{4 c_{0}-4 s+4 c_{2}\left(I_{2}\right)-2 c_{1}\left(I_{1}\right)-1}{5}
\end{aligned}
$$

$q_{2}^{2}$ and $I_{2}$ are all monotonically increasing in $s$. The conclusion, therefore, holds for the second firm.

For $s<p_{2}^{2}-p_{2}^{1} \leq s+1$, we have a similar conclusion by a similar method. Therefore, $q_{2}^{1}$ and $I_{1}$ are all monotonically decreasing in $s$, while $q_{2}^{2}$ and $I_{2}$ are all monotonically increasing in $s$.

Under $p_{2}^{2}<p_{2}^{1}$, we similarly have that $q_{2}^{1}$ and $I_{1}$ are all monotonically increasing in $s$, while $q_{2}^{2}$ and $I_{2}$ are all monotonically decreasing in $s$.

The conclusion is reached, and the proof is complete.

Remarks: This proposition illustrates that switching costs promote competition to attract consumers in the first period. This conclusion is highly consistent with the numerical simulation in Dubé et al. (2009) and supports their conclusions using another approach.

At the second period, as both firms aim to improve market share, larger switching costs yield a lower price for strong firms and a higher price for weak ones. Moreover, weak firms have more incentive to reduce price at the initial period than do strong firms. Under higher switching costs, there is less innovative investment by strong firms, while there is more innovative investment by weak ones.

There is an explanation for these phenomena. Higher switching costs diminish the advantages of strong firms, while innovation improves the position of weak firms. Accounting for innovation reduces the differences between firms.

In these calculations, we address the relationship between the cost of production and the price at the second stage. If $p_{2}^{2}-p_{2}^{1} \leq s,(7),(8)$ and (22) indicates $p_{2}^{1}=\frac{1}{2}+\frac{1}{2} c_{1}\left(I_{1}\right)$ and $p_{2}^{2}=\frac{1}{2}+s+\frac{1}{2} c_{1}\left(I_{1}\right)$. The strong firm's optimal price is determined by the production cost. The higher the marginal cost of the first firm, the higher price at the second stage. The weak firm prices according to $p_{2}^{2}=\frac{1}{2}+s+\frac{1}{2} c_{1}\left(I_{1}\right)$.

If $s<p_{2}^{2}-p_{2}^{1} \leq s+1,(13),(14)$ and (23) manifest $p_{2}^{1}=\frac{3}{7}-\frac{1}{7} p_{1}-\frac{s}{7}+\frac{4}{7} c_{1}\left(I_{1}\right)+\frac{1}{7} c_{2}\left(I_{2}\right)$ and $p_{2}^{2}=\frac{5}{7}-\frac{4}{7} p_{1}+\frac{3 s}{7}+\frac{2}{7} c_{1}\left(I_{1}\right)+\frac{4}{7} c_{2}\left(I_{2}\right)$. Higher marginal cost of any firm yields higher price at the second stage. If $1+s<p_{2}^{2}-p_{2}^{1}$, the strong firm optimally prices at both stages $p_{2}^{1}=\frac{1}{2}+\frac{1}{2} c_{1}\left(I_{1}\right)$ and $p_{1}^{*}=\frac{1}{2}+\frac{1}{2} c_{0}$.

\subsection{Compared with benchmark}

In this study, we consider the case without switching cost when the equilibrium price at the first period is denoted by $\bar{p}_{1}$, which satisfies $\bar{p}_{1} \in \underset{p_{1}}{\arg \max _{2}}\left\{\frac{1}{2}\left(p_{1}-c_{0}\right)\left(1-p_{1}\right)\right\}$. Compared with equilibrium price under switching costs $p_{1}^{*}$, we have the following conclusions: 
Proposition 2: $p_{1}^{*}<\bar{p}_{1}$. Innovative investment by firms with lower efficiency under switching costs is lower than it would be without switching costs, while innovative investment by firms with higher efficiency under switching costs is higher than it would be without switching costs.

Proof: The conclusion follows directly from the first statement of Proposition 1 as it applies to the case of $s=0$.

Remarks: This proposition concludes that switching costs bring about lower price, which is consistent with the numerical results of Cabral (2009), Doganoglu (2010) and Viard (2007) with moderate assumptions. These interesting conclusions are consistent with social phenomena. Actually, higher market share drives this conclusion. Additionally, under switching costs, firms of higher efficiency launch more innovative investment, and firms with lower efficiency reduce innovative investment. The explanation of these conclusions is similar to that of Proposition 1. Without switching costs, strong firms hold and exploit advantageous roles. Switching costs reduces the difference between firms, and strong firms lose a corresponding portion of their advantages.

In summary, under switching costs, strong firms price lower than they would without switching costs at both stages, while weak firms price lower at the first stage and higher at the second stage than they would without switching costs. Switching costs protect weak firms to launch less innovative investment and stimulate strong firms' innovation.

This is consistent with the empirical studies about China. Fang, Lerner and Wu (2017) studied the private firms (high efficiency firms) and state-owned enterprises (SOEs) with low efficiency. The intellectual property right (IPR) protection (which is the switching costs in this article) affects the innovation. Fang et al. (2017) identified that switching costs (IPR protection) strengthens firms' incentives to innovate and that strong (private sector) firms are more sensitive to IPR protection than weak firms (SOEs). According to data from China, Fang et al. (2017) compares firms' patenting rates of private firms and SOES. This table is collected from the interesting paper of Fang et al. (2017).

Table 1. A comparison innovation between private firms (high efficiency firms) and state-owned enterprises (SOEs). The tabulated number is the average patent stock in five years. For simplify, firms refer to privatization ones in recent years in China

\begin{tabular}{|l|c|c|c|}
\hline & SOEs & Private firms & Difference \\
\hline $\begin{array}{l}\text { Innovation and utility } \\
\text { patent stock }\end{array}$ & 0.416 & 1.495 & 1.079 \\
\hline
\end{tabular}

\section{Further discussion}

We now address the symmetric case. In this case, $c_{1}(I)=c_{2}(I)=c(I)$ for all $I$. At the first period, $p_{1}^{1}=p_{1}^{2}=p_{1}$, (1) and market clearing conditions jointly imply $q_{1}^{1}+q_{1}^{2}=1-p_{1}$. Actually, $p_{1}^{1}=p_{1}^{2}=p_{1}$. along with $q_{1}^{1}=q_{1}^{2}=q_{1}=\frac{1-p_{1}}{2}$, is a Nash equilibrium. By symmetry, we have $p_{2}^{1}=p_{2}^{2}=p_{2} \cdot q_{2}^{1}=q_{2}^{2}=\frac{1-p_{2}}{2}$. Therefore, we have $\int_{0}^{\theta_{i}^{*}} d \theta_{i}=\int_{0}^{\theta_{j}^{*}} d \theta_{j}=0$ and $q_{2}^{i, N}=\frac{p_{1}-p_{2}}{2}$. 
Hence,

$$
\begin{aligned}
& \pi^{1}=\left(p_{1}-c_{0}\right) \frac{1-p_{1}}{2}+\left[p_{2}-c(I)\right] \frac{1-p_{2}}{2}-\frac{1}{2} I^{2}, \\
& \pi^{2}=\left(p_{1}-c_{0}\right) \frac{1-p_{1}}{2}+\left[p_{2}-c(I)\right] \frac{1-p_{2}}{2}-\frac{1}{2} I^{2} .
\end{aligned}
$$

Therefore, several equilibriums must exist.

1) The equilibrium price at the second period is $\bar{p}_{2}$, which satisfies $\bar{p}_{2} \in \arg \max _{p_{2}}\left\{\frac{1}{2}\left(p_{2}-c(I)\right)\left(1-p_{2}\right)\right\}$. The corresponding output quantity is $\bar{q}_{2}=\frac{1-\bar{p}_{2}}{2}$. We further have $c^{\prime}(\bar{I}) \bar{q}_{2}=\bar{I}, \bar{p}_{2}=\frac{c(\bar{I})}{2}+\frac{1}{2}$ and $\bar{q}_{2}=\frac{1}{4}[1-c(\bar{I})]$. The equilibrium price at the first period satisfies $\bar{p}_{1} \in \arg \max _{p_{1}}\left\{\frac{1}{2}\left(p_{1}-c_{0}\right)\left(1-p_{1}\right)\right\}$ or $\bar{p}_{1}=\frac{c_{0}}{2}+\frac{1}{2}$ and $\bar{q}_{1}=\frac{1}{4}\left(1-c_{0}\right)$.

2) The equilibrium price at the second period is $\bar{p}_{2}$, which satisfies $\bar{p}_{2} \in \arg \max _{p_{2}}\left\{\frac{1}{2}\left(p_{2}-c(I)\right)\left(1-p_{2}\right)\right\}$. The corresponding output quantity is $\bar{q}_{2}=\frac{1-\bar{p}_{2}}{2}$. Moreover, we have $c^{\prime}(\bar{I}) \bar{q}_{2}=\bar{I}, \bar{p}_{2}=\frac{c(\bar{I})}{2}+\frac{1}{2}$ and $\bar{q}_{2}=\frac{1}{4}[1-c(\bar{I})]$. The equilibrium price at the first period satisfies $\bar{p}_{1}=c_{0}$ and $\bar{q}_{1}=\frac{1}{2}\left(1-c_{0}\right)$.

3) The equilibrium price at the second period is $\bar{p}_{2}$, which satisfies $\bar{p}_{2}=c(\bar{I})$. The corresponding output quantity is $\bar{q}_{2}=\frac{1-\bar{p}_{2}}{2}=\frac{1-c(\bar{I})}{2}$. We further have $c^{\prime}(\bar{I}) \bar{q}_{2}=\bar{I}$. The equilibrium price at the first period satisfies $\bar{p}_{1} \in \underset{p_{1}}{\arg \max _{2}}\left\{\frac{1}{2}\left(p_{1}-c_{0}\right)\left(1-p_{1}\right)\right\}$ or $\bar{p}_{1}=\frac{c_{0}}{2}+\frac{1}{2}$ and $\bar{q}_{1}=\frac{1}{4}\left(1-c_{0}\right)$.

4) The equilibrium price at the second period is $\bar{p}_{2}$, which satisfies $\bar{p}_{2}=c(\bar{I})$. The corresponding output quantity is $\bar{q}_{2}=\frac{1-\bar{p}_{2}}{2}=\frac{1-c(\bar{I})}{2}$. Moreover, we therefore have $c^{\prime}(\bar{I}) \bar{q}_{2}=\bar{I}$. The equilibrium price at the first period satisfies $\bar{p}_{1} \in \arg \max _{p_{1}}\left\{\frac{1}{2}\left(p_{1}-c_{0}\right)\left(1-p_{1}\right)\right\}$ or $\bar{p}_{1}=\frac{c_{0}}{2}+\frac{1}{2}$ and $\bar{q}_{1}=\frac{1}{4}\left(1-c_{0}\right)$.

5) The equilibrium price at the second period is $\bar{p}_{2}$, which satisfies $\bar{p}_{2} \in \underset{p_{2}}{\arg \max }\left\{\frac{1}{2}\left(p_{2}-c(I)\right)\left(1-p_{2}\right)\right\}$. The corresponding output quantity is $\bar{q}_{2}=\frac{1-\bar{p}_{2}}{2}$. We further have $c^{\prime}(\bar{I}) \bar{q}_{2}=\bar{I}, \quad \bar{p}_{2}=\frac{c(\bar{I})}{2}+\frac{1}{2} \quad$ and $\bar{q}_{2}=\frac{1}{4}[1-c(\bar{I})]$. The equilibrium price at the first period satisfies $\bar{p}_{1}$ as the solution of $\pi^{1}=\left(p_{1}-c_{0}\right) \frac{1-p_{1}}{2}+\left[\bar{p}_{2}-c(\bar{I})\right] \frac{1-\bar{p}_{2}}{2}-\frac{1}{2} \bar{I}^{2}=0$. 
6) The equilibrium price at the first period satisfies $\bar{p}_{1} \in \underset{p_{1}}{\arg \max _{2}}\left\{\frac{1}{2}\left(p_{1}-c_{0}\right)\left(1-p_{1}\right)\right\}$ or $\bar{p}_{1}=\frac{c_{0}}{2}+\frac{1}{2}$ and $\bar{q}_{1}=\frac{1}{4}\left(1-c_{0}\right)$. The equilibrium price at the second period is $\bar{p}_{2}$, which satisfies $\pi^{1}=\frac{1}{8}\left(1-c_{0}\right)^{2}+\left[\bar{p}_{2}-c(\bar{I})\right] \frac{1-\bar{p}_{2}}{2}-\frac{1}{2} \bar{I}^{2}=0, \bar{q}_{2}=\frac{1}{4}[1-c(\bar{I})]$ and $c^{\prime}(\bar{I}) \bar{q}_{2}=\bar{I}$.

According to the above six cases, we have

Proposition 3: Switching costs have no effects on the equilibrium under symmetry.

Remarks: Under symmetry, switching costs have no effects on the equilibrium. This conclusion seems surprising. But an explanation might be formulated as follows: switching costs improve market power. Under symmetry, two firms compete fiercely, diminishing the possible gain in market power from switching costs.

This conclusion is also rational with reality. Parker and Van Alstyne (2018) addressed the effects of platform on innovation. Actually, opening a platform typically reduces user switching costs and affects innovation. Parker and Van Alstyne (2018) argued that reducing switching costs have no significant effects on innovation under some cases. Actually, under fierce competition, firms almost play symmetric position. Therefore, the conclusions of Parker and Van Alstyne (2018) support the above results.

\section{Concluding remarks}

This paper assumes the concave properties of the cost function, which is also launched in the general economic literature. This study develops models for the role of innovation under switching cost, capturing the relationship between innovative investments and switching costs. The results of this paper illustrate that switching costs improve competition. This study argues that switching costs cause lower price. More importantly, this paper shows that the effects of switching costs are different between difference firms. Under asymmetric equilibrium, switching costs deter innovative investment for less efficient firms, while encouraging innovation of firms with higher efficiency. Under symmetric cases, switching costs have no relation with innovative investment.

This paper extends switching costs theory by involving exploitative innovation and brand loyalty. But one of the most vertical limitations of this study is that all the conclusions are obtained by theoretical analysis without data support. Further study can try to carry out empirical analysis. Another limitation of this paper is that we assume switching costs are exogenous but there are many cases with endogenous switching costs. It is interesting to address endogenous switching costs. Besides, this study assumes that innovative investment is not known by consumers, although when innovative investment is observed by consumers, firms with more innovative investment attract more consumers. Innovative investment acts as a type of commitment. In this case, strong firms and firms with more innovative investment play advantageous positions and attract more consumers. This topic warrants further research.

Our conclusions have some policy implication. Diminishing switching costs can promote the innovation of the higher efficiency. Moreover, subsiding with higher efficiency firm's innovation can improve the total R\&D. 


\section{Acknowledgement}

This work is partially supported by National Natural Science Foundation of PRC (71771057, 71401057, 71703028), Guangdong Social Science Foundation (GD17XYJ23), Collaborative Innovation Center of Scientific Finance \& industry, and, Innovative Group Foundation (Humanities and Social Sciences) for Higher Education of Guangdong Province (2015WCXTD009), and the Key Program of National Natural Science Foundation of China (71633002; 71333004).

\section{References}

Burnham, T. A., Krels, J. K., \& Mahajan, V. (2003). Consumer switching costs: A typology, antecedents and consequences. Journal of the Academy of Marketing Science, 31(2), 109-126. https://doi.org/10.1177/0092070302250897

Cabral, l, L. (2009). Small switching costs lead to lower prices. Journal of Marketing Research, 46(4), 449-451.

Capone, G., Malerba, F., \& Orsenigo, L. (2013). Are switching costs always effective in creating firstmover advantage? The moderating role of demand and technological regimes. Long Range Planning, 46, 348-368. https://doi.org/10.1016/j.lrp.2013.06.001

Chen, Y. H., Nie, P. Y., \& Wang, X. H. (2015). Asymmetric duopoly competition with innovation spillover and input constraints. Journal of Business Economics and Management, 16(6), 1124-1139. https://doi.org/10.3846/16111699.2013.823104

Chen, Y. H., Nie, P. Y., \& Huang, J. B. (2017). Duopoly innovation with monopoly debater. Revista brasileira de gestão de negócios, 19(63), 104-117. https://doi.org/10.7819/rbgn.v19i63.2462

Chen, Y. H., Nie, P. Y., \& Wen, X. W. (2015b). Analysis of innovation based on financial structure. Economic Research-Ekonomska Istraživanja, 28(1), 631-640. https://doi.org/10.1080/1331677X.2015.1087327

Chen, Y. H., Wen, X. W., Wang, B., \& Nie, P. Y. (2017). Agricultural pollution and regulation How to subsidize agriculture?. Journal of Cleaner Production, 164, 258-264. https://doi.org/10.1016/j.jclepro.2017.06.216

Chen, Y. M. (1997). Paying customers to switching. Journal of Economics and Management Strategy, 6(4), 877-897. https://doi.org/10.1162/105864097567291

Chen, Y. M., \& Sappington, D. (2010). Innovation in vertically related markets. Journal of Industrial Economics, 58(2), 373-401. https://doi.org/10.1111/j.1467-6451.2010.00414.x

Chen, Y. M., \& Pearcy, J. (2010). Dynamic pricing: when to entice brand switching and when to reward consumer loyalty. RAND Journal of Economics, 41(4), 674-685. https://doi.org/10.1111/j.1756-2171.2010.00116.x

Doganoglu, T. (2010). Switching costs, experience goods and dynamic price competition". QME- Quantitative Marketing and Economics, 8(2), 167-205. https://doi.org/10.1007/s11129-010-9083-y

Dubé, J.-P., Hitsch, G. J., \& Rossi, P. E. (2009). Do switching costs make markets less competitive?, Journal of Marketing Research, 46(4), 435-445. https://doi.org/10.1509/jmkr.46.4.435

Fang, L. H., Lerner, J., \& Wu, C. (2017). Intellectual property rights protection, ownership, and innovation: Evidence from China. The Review of Financial Studies, 30(7), 2446-2477. https://doi.org/10.1093/rfs/hhx023

Farrell, J., \& Klemperer, P. (2007). Chapter 31 Coordination and Lock-Ii: Competition with switching costs and network effects. Handbook of Industrial Organization, 3, 1967-2072. https://doi.org/10.1016/S1573-448X(06)03031-7 
Farrell, J., \& Saloner, G. (1985). Standardization, compatibility, and innovation. RAND Journal of Economics, 16(1), 70-83. https://doi.org/10.2307/2555589

Fischer, J. H., \& Ross, J. M. (2014). Timing the start of material substitution projects: Creating switching options under volatile material prices. Journal of Product Innovation Management, 31(3), 567-583. https://doi.org/10.1111/jpim.12114

Haj-Salem, N., \& Chebat, J. C. (2014). The double-edged sword: The positive and negative effects of switching costs on customer exit and revenge. Journal of Business Research, 67, 1106-1113. Retrieved from http://www.investopedia.com/terms/s/switchingcosts.asp\#ixzz1lBMQCO4l. https://doi.org/10.1016/j.jbusres.2013.05.050.

Jabarnejad, M., \& Valenzuela, J. (2016). Optimal investment plan for dynamic thermal rating using benders decomposition. European Journal of Operational Research, 248(3), 917-929.

https://doi.org/10.1016/j.ejor.2015.08.010

Klemperer, P. (1987). The competitiveness of markets with switching costs. Rand Journal of Economics, 18(1), 138-150. https://doi.org/10.2307/2555540

Klemperer, P. (1995). Competition when consumers have switching costs: An overview with applications to industrial organization, macroeconomics, and international trade. Review of Economic Studies, 62(4), 515-539. https://doi.org/10.2307/2298075

Morita, H., \& Waldman, M. (2010). Competition, monopoly maintenance and consumer switching cost. American Economic Journal: Microeconomics, 2(1), 230-255. https://doi.org/10.1257/mic.2.1.230

Nie, P. Y. (2014). Effects of capacity constraints on mixed duopoly. Journal of Economics, 112(3), 283294. https://doi.org/10.1007/s00712-013-0362-4

Nie, P. Y. (2018. Comparing horizontal mergers under Cournot with Bertrand competitions. Australian Economic Papers, 57(1), 12-37. https://doi.org/10.1111/1467-8454.12053

Nie, P. Y., \& Chen, Y. H. (2012). Duopoly competitions with capacity constrained input. Economic Modelling, 29(5), 1715-1721. https://doi.org/10.1016/j.econmod.2012.05.022

Nie, P. Y., Wang, C., Chen, Z. Y., \& Chen, Y. H. (2018). A theoretic analysis of key person insurance. Economic Modelling, to appear. https://doi.org/10.1016/j.econmod.2017.12.020

Nie, P. Y., Yang, Y. C., Chen, Y. H., \& Wang, Z. H. (2016). How to subsidize energy efficiency under duopoly efficiently?. Applied Energy, 175, 31-39. https://doi.org/10.1016/j.apenergy.2016.04.105

Parker, G., \& Van Alstyne, M. (2018). Innovation, openness, and platform control. Management Science, to appear. https://doi.org/10.1287/mnsc.2017.2757

Sacco, D., \& Schmutzler, A. (2011). Is there a U-shaped relation between competition and investment. International Journal of Industrial Organization, 29(1), 65-73.

https://doi.org/10.1016/j.ijindorg.2009.09.003

Shen, N., \& Su, J. (2015). A comparison of different contract forms for consumers with switching costs and changed preferences. Economic Modelling, 50, 19-26.

https://doi.org/10.1016/j.econmod.2015.05.014

Viard, B. (2007). Do switching costs make markets more or less competitive? The case of 800-number portability. RAND Journal of Economics, 38(1), 146-163. https://doi.org/10.1111/j.1756-2171.2007.tb00049.x

Vives, X. (2008). Innovation and competitive pressure. The Journal of Industrial Economics, 56(3), 419469. https://doi.org/10.1111/j.1467-6451.2008.00356.x

Wang, C., Nie, P. Y., Peng, D. H., \& Li, Z. H. (2017). Green insurance subsidy for promoting clean production innovation. Journal of Cleaner Production, 148, 111-117. https://doi.org/10.1016/j.jclepro.2017.01.145

Wang, R. Q., \& Wen, Q. (1998). Strategic invasion in markets with switching costs, Journal of Economics and Management Strategy, 7(4), 521-549. https://doi.org/10.1162/105864098567506 
Yang, Y. C., Nie, P. Y., Liu, H. T., \& Shen, M. H. (2018). On the welfare effects of subsidy game for renewable energy investment: toward a dynamic equilibrium model. Renewable Energy, 121, 420-428. https://doi.org/10.1016/j.renene.2017.12.097

Yang, Y. C., \& Nie, P. Y. (2015). R\&D subsidies under asymmetric Cournot competition. Economic research-Ekonomska istraživanja, 28(1), 830-842. https://doi.org/10.1080/1331677X.2015.1088791 